\title{
Characterising feedback cultures in higher education: an analysis of strategy documents from 134 UK universities
}

\author{
Naomi E. Winstone ${ }^{1,2}$ (D) \\ Accepted: 24 January 2022 / Published online: 26 February 2022 \\ (c) The Author(s) 2022
}

\begin{abstract}
Feedback can be framed as a one-way transmission of information driven by educators, or as a two-way process, in which students' agentic participation is critical to its success. Despite calls for a shift away from the former framing towards the latter, transmissionfocused models of feedback continue to dominate practice internationally. Approaches to feedback in any given setting are likely influenced by the dominant feedback culture. The present study aimed to characterise 'feedback cultures' within higher education by systematically examining how feedback is framed in 134 UK universities' (a) educational strategies and (b) Teaching Excellence Framework (TEF) Provider statements. These documents serve to encapsulate each institution's views of excellence and best-practice; nevertheless, analysis of the documents revealed a stronger focus on the transmission of feedback comments than on supporting students' learning through feedback processes. Linguistically, students were positioned passively within the documents, as being on the receiving end of teachers' actions, rather than actively driving their own learning through feedback. These findings inform a framework for conceptualising feedback cultures in higher education, which positions approaches to feedback design, feedback processes and the evaluation and development of feedback on a continuum from transmission-focused to learning-focused. It is argued that strategy documents shape practice in subtle ways; in order to shift towards learning-focused feedback cultures, consideration must be given to how students' roles and responsibilities are positioned in both policy and practice.
\end{abstract}

Keywords Assessment · Feedback · Transmission-focused $\cdot$ Learning-focused $\cdot$ Feedback cultures

There are few dimensions of practice in contemporary higher education (HE) internationally that receive the same level of scrutiny as assessment and feedback. On the basis of metrics such as the UK's National Student Survey (NSS) and the Australian Course Experience Questionnaire (CEQ), teaching staff are often encouraged to pay greater attention to the provision of feedback such as the detail and framing of their comments and the turnaround time

Naomi E. Winstone

n.winstone@ surrey.ac.uk

1 Surrey Institute of Education, University of Surrey, Guildford, UK

2 Centre for Research in Assessment and Digital Learning, Deakin University, Melbourne, Australia 
within which comments are returned to students (Winstone \& Boud, 2019a). Such a view of feedback as teaching (i.e. giving students information about their work) is increasingly framed as outdated (Boud \& Molloy, 2013; Carless, 2015; Winstone \& Carless, 2019). In its place is a growing recognition that the actions of students, in making sense of and applying feedback information, are fundamental to the impact of feedback processes (Carless \& Boud, 2018; Henderson, Ajjawi, et al., 2019a). In practice, this shift requires the positioning of educators as facilitators of student learning through feedback rather than mere providers of feedback information and the positioning of students as active participants in an ongoing process rather than passive recipients of comments (Carless, 2015).

This distinction has important implications for how we evaluate and develop quality in education. As Henderson et al. (2019b, p. 4) argue:

This shift of thinking from a teaching-centred process to a learning-centred one, means we have to look to new ways of thinking about the quality of feedback... Instead of only focusing on the quality of the teacher's input, we need to consider the quality of the whole process, including the active role of students.

Whilst measures such as the NSS and CEQ have the potential to shape assessment and feedback practices, given their role in raising quality and standards in HE (Shah \& Richardson, 2016; Tomlinson et al., 2020), student ratings do not necessarily improve the quality of learning and teaching (Roxå et al., 2021), In fact, the drive to improve performance on metrics may in fact promote the antithesis of student-centred approaches; most national-level student satisfaction instruments frame quality as represented by teacher transmission rather than student agency (Winstone et al., 2021a). Thus, achieving a shift towards learning-focused approaches to feedback is likely to require large-scale changes to the culture of feedback in $\mathrm{HE}$, incorporating changes to both policy and practice.

Despite a large literature on the practice of feedback in HE, the framing of feedback in policy and strategy has been largely overlooked. Institutional policies and strategies set out what is valued by the institution and how individual educators are expected to enact feedback processes. Such documentation also positions students in particular ways, framing expectations around their roles and responsibilities in feedback. A critical analysis of the positioning of students and educators in strategic documentation is important because the messages conveyed by these documents, either explicitly or implicitly, can significantly shape the enactment of practice 'on the ground', whereby in 'their day-to-day activities as practitioners, academics attach meaning to various aspects of policy as they interact with it' (Newton, 2003, p.432).

The present study builds on growing international interest in feedback cultures (e.g. Page et al., 2021; Ramani et al., 2018; Watling et al., 2020) and contributes to the international literature on feedback through a large-scale national-level analysis of feedback cultures and the positioning of students within strategic documentation. The analysis presents novel insights into institutional emphasis on transmission-focused or learning-focused feedback approaches, which are used to inform the development of a framework for conceptualising feedback cultures in HE.

\section{Transmission-focused versus student-focused approaches to education}

In their seminal work, Trigwell and Prosser (1996) drew a key distinction between transmission-focused and student-focused approaches to education. In the former approach, emphasis is placed on the actions of the teacher in transmitting information to students. In contrast, a 'student-focused approach is one which has the student as the focus of 
activities... it matters more what the student is doing and learning than what the teacher is doing or covering' (Trigwell et al., 1999, p. 58). These approaches are related to the conceptions of learning held by educators, where

Those teachers who conceive of learning as information accumulation to meet external demands also conceive of teaching as transmitting information to students, and approach their teaching in terms of teacher-focused strategies. On the other hand, those teachers who conceive of learning as developing and changing students' conceptions, conceive of teaching in terms of helping students to develop and change their conceptions and approach their teaching in a studentfocused way. (Trigwell et al., 1999, p.59)

Two crucial and inter-related findings emerged from this body of research. First, students are more likely to adopt deep rather than surface approaches to learning when their teachers adopt student-focused rather than transmission-focused approaches to teaching (e.g. Trigwell et al., 1999). Second, the adoption of a student-focused approach to teaching is associated with superior learning outcomes in students (e.g. Trigwell \& Prosser, 1991).

These ideas are echoed in the research literature on feedback. In a comprehensive meta-review of feedback research, Van der Kleij et al. (2019) recently drew a distinction between transmission and dialogic models of feedback. In the former, the student merely receives feedback, with no active role in the process. This model, which can be seen as aligning with Trigwell and Prosser's transmission-focused teaching approach, represents feedback as a product to be transmitted, in a process driven by teachers. Conversely, and aligned with Trigwell and Prosser's student-focused teaching approach, is a dialogic feedback model wherein the student has a substantial role. Here, the role of the teacher is to guide feedback processes in order to facilitate student learning, where students possess the agency to participate in feedback processes to support learning and self-regulation. Students are positioned as active partners in feedback processes with the capacity to provide, seek and use feedback. Van der Kleij et al. conclude that whilst the literature is shifting towards recognising students' important role in the feedback process, 'traditional conceptualisations of feedback remain popular' (van der Kleij et al., 2019, p. 319). This finding is echoed in practice, where 'approaches to assessment and feedback have remained obstinately transmission-focused, even in contexts where there is general acceptance of more student-centred and participatory teaching practices' (O'Donovan et al., 2016, p. 939).

There are likely complex and layered influences on practice, but understanding why practice is not generally developing in line with a learning-focused approach requires us to examine feedback cultures. For example, Winstone and Boud (2019b) discussed differences in learning-focused and transmission-focused feedback cultures, demonstrating that participants in the UK espoused a more dominant transmission-focused approach to feedback than their counterparts in Australia. One potential reason for these differences relates to institutions' strategic priorities and policies within a national context, which is an important layer of the feedback culture that forms the focus of the present study.

\section{Feedback cultures: the role of strategy and policy}

The process and practice of feedback do not take place in a contextual vacuum; the ways in which feedback is enacted are influenced by intrapersonal and interpersonal factors, as well as by the proximal and distal environments in which an individual works (Winstone 
\& Carless, 2019). These factors interact to create feedback cultures, which for the purposes of this paper are defined through an organisational lens (Watling et al., 2020), representing shared beliefs, values and repertoires of practice within a working environment. In the context of feedback, the culture represents 'the values and beliefs of the individuals involved and how these shape the norms and expectations for feedback interactions' (Watling et al., 2020 , p. 294). Thus, a given culture might be more closely aligned with a transmissionfocused approach to feedback, or might be more closely aligned with a learning-focused approach. Which culture predominates in a given setting is influenced by 'a complex and dynamic interaction of the implicit and explicit messages about feedback to which [individuals] are exposed, their own beliefs, values and professional development, and institutional policies and procedures' (Winstone \& Boud, 2019b, p. 413). In a discussion of 'learning cultures', James (2014) identifies the role of policies, quality regimens and accountability processes as important influences.

In a 1998 survey of UK HE institutions' learning and teaching strategies, Gibbs et al. (2000) identified the importance of 'the kind of culture sought by the institution (for example a 'learning organisation' or a 'student-centred' culture) and the mechanisms which might help to achieve it' (p. 362). Their analysis showed that one of the stated purposes of learning and teaching strategies was to facilitate a broad shift in culture or conceptions relating to education, such as a shift from teacher- to student-focused approaches (Gibbs et al., 2000). Smith (2008) presented a critical discourse analysis of nine UK institutions' learning and teaching strategies, identifying that students were often framed as passive objects of universities' initiatives, which 'relegates the student to the receiving end of any activity performed by the actor' (p. 402). Similarly, Voce (2015) analysed institutional policies on the electronic management of assessment and found that linguistically, students were most commonly 'acted upon' rather than actors.

\section{The present study}

This study sought to adopt an empirical approach to defining feedback cultures, through a detailed analysis of how feedback practices are positioned within institutions' strategy documents. In order to take a national-level approach to analysis, the UK was selected as the context within which to explore feedback cultures due to heavy external regulation of $\mathrm{HE}$, most notably through the introduction of the Teaching Excellence Framework (TEF). Institutional approaches to assessment and feedback were therefore scrutinised through a document analysis of two sources of data from the UK: institutions' education strategies; and their TEF submissions. The addition of TEF submissions alongside institutions' own strategies provided a valuable lens on the framing of feedback cultures. In particular, the influence of external regulation on the approaches espoused in strategic documentation can make such documents act as 'corporate tools' (Goodyear \& Ellis, 2019), so the opportunity to scrutinise more than one type of artefact with different primary purposes was central to the development of an evidence-informed framework for conceptualising feedback cultures. Two key research questions were addressed using these data: (1) How are students positioned in feedback processes within strategy documentation?; and (2) What characterises feedback cultures in Higher Education? 


\section{Methods}

\section{Document selection}

The data corpus for this study consisted of strategy documents available within the public domain that encapsulate the approaches to feedback taken by UK Higher Education Institutions (HEIs). TEF Provider Submissions and education strategies were compiled for 134 UK HEIs. This sample size represents all HEIs (universities and specialist institutions) that made a TEF submission in 2017. Further Education Colleges and Alternative Providers were not included. TEF Provider Submissions for the 2017 TEF Year 2 exercise were downloaded from the HEFCE/OfS website, and a research assistant searched each HEI's website for their education strategy.

\section{Education strategies}

The recommendation for UK HEIs to develop education strategies was laid out in the Dearing Report (NCIHE, 1997). Education strategies represent to a greater or lesser extent an institution's educational ethos and provide the institution with an opportunity to articulate priorities, processes and what makes their institution unique.

In some cases, HEIs outlined their strategic approaches to education within a broader corporate strategy. The approach taken here was to use whatever strategy pertaining to education had been published to an externally facing audience. There was significant variability in the style and structure of education strategies, but common areas of focus included technology-enhanced learning, assessment and feedback and student employability.

\section{Teaching Excellence Framework (TEF) submissions}

The UK Teaching Excellence Framework (TEF) was first implemented in 2017, as a government strategy to raise the profile of teaching (Ashwin, 2017; Berger \& Wild, 2016), to further perpetuate growth in excellence (Barkas et al., 2019) and to determine which HEIs would be entitled to increase tuition fees. Universities which entered the process were assessed in three areas: teaching quality; learning environment; and student outcomes and learning gain. The assessment was based on a series of existing metrics (including some scales from the NSS, student continuation metrics and graduate employment metrics), alongside a 15-page narrative in which HEIs had the opportunity to contextualise their metrics and provide a claim for the excellence of their educational initiatives. On the basis of the assessment, institutions were awarded a rating of Gold, Silver, or Bronze (for a more detailed discussion of the TEF, see Barkas et al., 2019). There is ongoing controversy around the validity of the TEF (see Deem \& Baird, 2019), recognising in part that 'teaching excellence is a contested, value-laden concept' (Skelton, 2005, p. 4). Nevertheless, the 15-page narratives, publicly available, serve as a rich dataset representing how HEIs frame the quality of their educational provision.

\section{Analytic approach}

Documents were collated and analysed according to the document analysis method presented by Bowen (2009). This is a systematic approach to the analysis of documentary 
evidence, providing insight into the wider context and environment pertinent to a focal area of study.

The data corpus was compiled by extracting from documents all text pertaining to the practice and process of feedback. Two research assistants (RAs) were trained to identify and extract relevant excerpts. Each RA was primarily responsible for either the TEF submissions or the education strategies, with the accuracy of their extraction confirmed by the other RA. Each extracted section of text was treated as a separate paragraph for purposes of analysis. Extracted text for TEF Provider submissions consisted of 21,410 words across 572 paragraphs; for education strategies, 7692 words across 408 paragraphs were extracted.

The data corpus was analysed in three ways through an interpretivist approach, using inductive and deductive coding alongside linguistic analysis. Table 1 presents the relationship between the two research questions, the analytic approaches and the aims of each analysis.

The first analytical approach involved linguistic analysis to explore whether students were positioned as actors in feedback processes, or 'acted upon' (Voce, 2015). The positioning of students as active or passive in feedback processes is an important part of the feedback culture, and through quantitative linguistic analysis, it is possible to gain insight into such positioning across the corpus as a whole. All document extracts were entered into the corpus linguistics tool 'Sketch Engine' as a data corpus, and the Word Sketch feature was used to identify the frequency of verbs used for which feedback was the object, thus representing the positioning of students in feedback processes. Three categories of verbs were of interest: verbs representing teacher actions (e.g. provide, give, return, deliver); verbs representing actions of students that signal passive reception of feedback (e.g. receive, get, view); and verbs representing a more agentic role for students (e.g. use, apply, analyse).

The second analytical approach involved inductive coding of the document extracts according to the area of practice or process on which they focused. This coding was conducted by 2 RAs independently who iteratively discussed and refined the coding scheme. Codes were then combined to form themes using an iterative process; 12 initial thematic areas were identified (technology; inclusivity; timing of feedback; types of feedback, e.g. peer, formative; research-informed practices; recognition of staff practice; authenticity; assessment and feedback literacies; quality assurance processes; staff training and development; student satisfaction; and student involvement in feedback processes). These were further combined into three primary themes: feedback design; feedback practice and purpose; and development and evaluation of feedback processes. Themes were identified through a recursive process: codes were sorted into candidate themes according to commonality in the dimension of feedback they represent (e.g. type of practice, improvement of practice). Themes were refined by revisiting coded extracts under each of these themes and by assessing the validity of the themes across the data corpus (Braun \& Clarke, 2006).

The third analytical approach involved deductive coding in NVivo. Here, the coding cut across the broad themes to examine the framing of accounts of practice. Two codes were applied: (1) strategies and approaches that focused primarily on the transmission of feedback comments from educator to student; and (2) strategies and approaches that focused primarily on facilitating student learning through feedback. Whereas these two approaches are clearly interlinked, the coding was based on prior theoretical stances that broadly reflect the actions of the teacher versus the actions of the student. Thus, the transmissionfocused code reflected cognitivist practices and activities that place primary emphasis on 


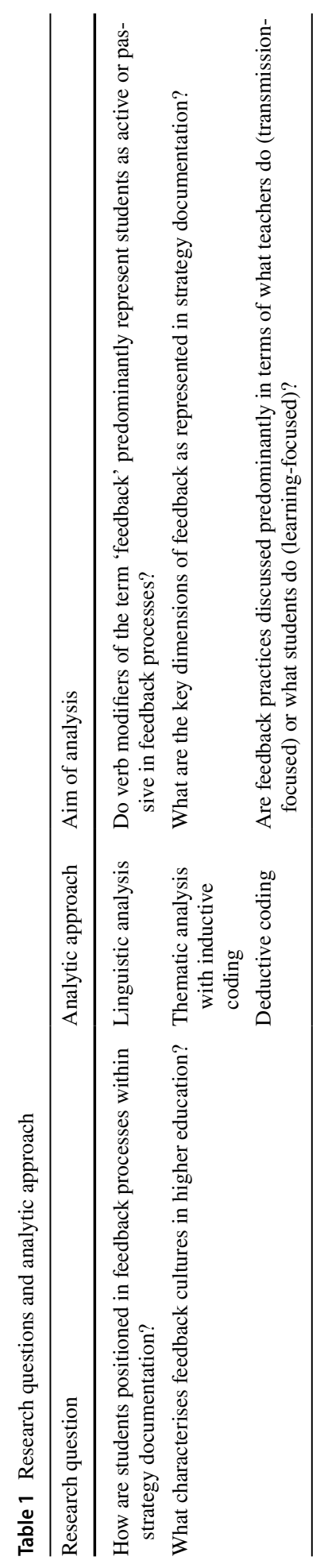


the behaviours of teachers, where teachers provided or delivered something. In contrast, the learning-focused code reflected socioconstructivist practices that placed primary emphasis on facilitating student learning. This code reflects Trigwell et al.'s (1999) representation of 'student-focused' approaches.

The coding was undertaken by the author, with intercoder agreement assessed using the procedures outlined by Lombard et al. (2002). First, reliability was assessed informally during coder training, where a small number of extracts that had been coded by the author were coded independently by a second coder. Next, reliability was assessed formally in a pilot test, where 30 extracts were coded independently by the author and the second coder (Krippendorff's alpha $=.86,95 \%$ CI $[.67,1.00]$ ). Finally, $10 \%$ of the sample (110 extracts) was coded independently by the author and the second coder. Agreement was deemed acceptable (Krippendorff's alpha $=.79,95 \%$ CI $[.66, .92]$ ), given the exploratory nature of the research and the use of a conservative index (Lombard et al., 2002).

\section{Findings}

The findings from the document analysis are structured according to research question and are discussed with reference to illustrative quotations from the documents themselves. Institutions are not directly identified in the illustrative quotations, but the source of each quotation is indicated as TEF Provider Submissions (TPS) or education strategies (ES). The respective institution's rating in the Year 2 TEF is also indicated (Gold, Silver, or Bronze), as well as the type of institution, represented as Russell Group (RG; prestigious research-intensive universities), post-92 (P92; newer, teachingfocused universities), specialist institution (SI; conservatoires, discipline-specific colleges), or dual intensive (DI; pre-92 institutions falling outside of the research-intensive Russell Group).

\section{How are students positioned in feedback processes within strategy documentation?}

The linguistic analysis (see Fig. 1) identified that in TEF Provider Submissions, there were a total of 157 collocations where the term 'feedback' was modified by a verb; for the education strategies, there were 43 such collocations in total. Exploring the percentage of these collocations for each verb category of interest revealed that the most common modifiers of the term 'feedback' were verbs pertaining to transmission-focused actions of teachers, representing the provision of feedback (e.g. provide, give, return, deliver). Such language positions students as passive receivers of information, for example, where 'all students receive feedback on summative assessment at the earliest opportunity' (TPS, Gold, P92). This relegates students to being 'acted upon' rather than actively involved in the feedback process. Student-focused verbs were rarer, and in many cases, these represented passive actions (e.g. receive, get, view). Whilst such verbs position students as actors in the feedback process, their actions are limited and could represent surface processing of comments, for example, when enabled to 'view their online assessment feedback easily' (TPS, Silver, $\mathrm{RG}$ ). Verbs pertaining to student use of feedback were very rare (e.g. use, apply, analyse), and were used when describing approaches to supporting students' active involvement in feedback processes, such as their capacity to 'use feedback effectively' (ES, Gold, DI). 


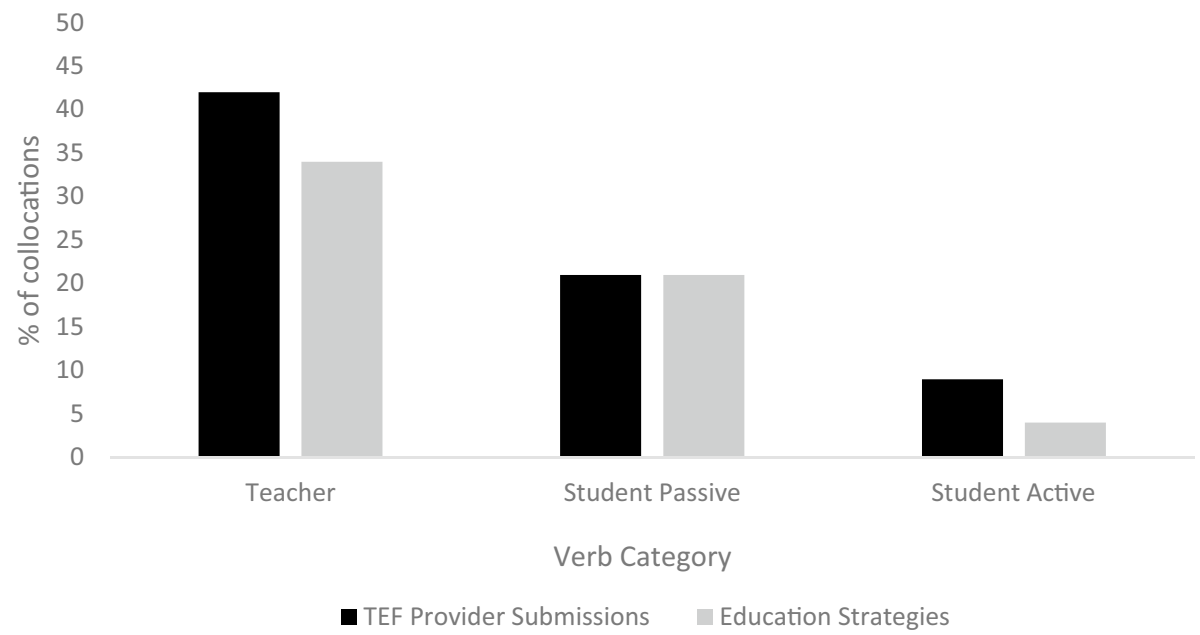

Fig. 1 Percentage of collocations representing verbs where feedback is the object across categories of verbs representing teacher actions, verbs representing passive student actions and verbs representing active student actions

Verbs representing the provision and surface receiving of feedback imply a transactional, cognitivist representation of the process. It is verbs aligned with the use of feedback that incorporate student agency into the process, and these were rare.

\section{What characterises feedback cultures in higher education?}

Within their TEF submissions, $99 \%$ of institutions made reference to feedback. Within their education strategies, $65 \%$ of institutions referenced their approaches to feedback. Deductive coding of all data excerpts revealed that the presentation of activities and initiatives pertaining to feedback were predominantly transmission-focused, that is, they focused on the actions of teachers rather than on the facilitation of student learning through feedback (see Fig. 2). These differences are explored in greater depth below.

Inductive coding and thematic analysis of the document extracts led to the identification of three broad themes representing approaches to feedback: drivers of decision-making in the design of feedback processes; the enactment of feedback processes in terms of the nature of feedback opportunities; and approaches to evaluating and developing the effectiveness of feedback processes. Within each of these broad themes, transmission-focused and learning-focused approaches were identified, which are discussed as distinguishing features of different feedback cultures.

\section{Feedback design}

Different approaches to feedback could be distinguished by the articulated rationale for decisions regarding the design of the feedback environment. Learning-focused approaches were signified by a strong pedagogic design stance, where the rationale for decision-making was driven by the perceived impact on student learning. In contrast, transmission-focused 


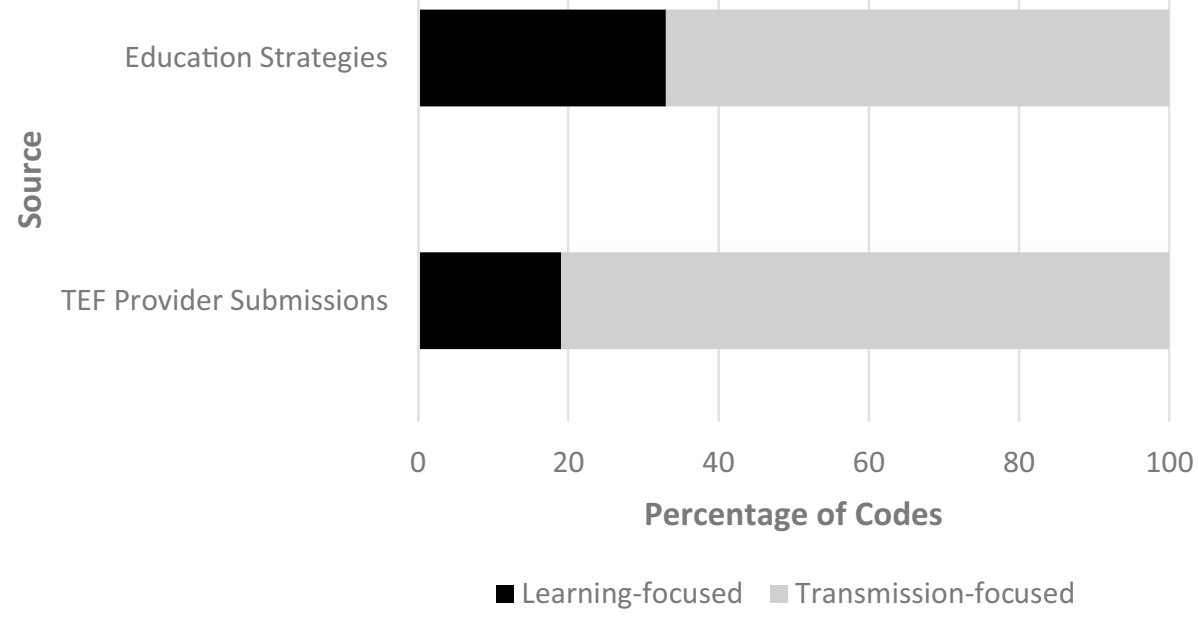

Fig. 2 Percentage of learning-focused and transmission-focused codes across document types

approaches were driven by pragmatic design decisions purely focused on the actions of teachers. This difference is clearly illustrated within discussions of the use of technology in feedback processes. The most commonly articulated rationale for the use of technology was to streamline feedback processes enacted by teachers, for example, through discussion of 'electronic management of assessment (EMA) to enable a systematic and standard approach...to quality electronic feedback' (TPS, Silver, P92). A transmission-focused approach also involved setting what may appear to be arbitrary targets for teachers' use of technology in feedback processes; for example, ' $85 \%$ of all appropriate submission and feedback via VLE' (ES, Gold, SI) and ' $70 \%$ of appropriate coursework marked using GradeMark' (ES, Bronze, SI).

Many documents made reference to the use of technology to enhance the actions of teachers, in terms of the provision and delivery of feedback information. This emphasis on what teachers, not students, do is a clear hallmark of a transmission-focused approach. Many claims for excellence in the use of technology in feedback processes emphasised the 'provision' of comments through '... the provision of digital feedback on student assignments' (ES, Silver, P92), including the use of tools to 'provide students with digital feedback' (TPS, Gold, RG). This was in some cases a requirement, where strategies mandated to 'ensure that all written summative feedback is provided electronically to students' (ES, Silver, SI).

There were some examples within documentation of institutions seeking to harness the specific affordances of technology in promoting students' learning, beyond merely replicating the transmission of comments in a digital medium, for example, through 'an emphasis on supporting learning rather than novelty' (TPS, Silver, RG). Others described specific uses of technology such as providing 'just-in-time' formative feedback, through the use of 'computer-based assessment, in both formative and summative contexts, where feedback in this case can be instantaneous' (TPS, Gold, P92). Similarly, one provider described using technology 'to extend the ways in which assessment and feedback can enhance learning... 
for example online discussion forums for formative peer review' (TPS, Gold, DI). However, many unsupported claims were made about the benefits of technology as increasing 'the clarity of feedback, making it easier for students to use in their learning' (TPS, Bronze, DI) and resulting in 'improved student engagement with feedback on assessed work' (TPS, Bronze, P92).

Approaches to design that indicate a transmission-focused approach were also replicated in discussions of mandated and monitored timing for the return of feedback information, for example where feedback 'must be returned within three weeks' (TPS, Gold, DI), or within 'a 15-day turnaround' (TPS, Silver, P92). This focus can lead to an arms race to further reduce turnaround times, with one provider boasting 'sector-leading student feedback return times (10 working days for the majority of work)' (TPS, Silver, P92) and another provider setting what appear to be quite arbitrary targets, such as ' $50 \%$ of feedback returned to students within 3 weeks and the remaining within 4 weeks' (ES, Bronze, SI). These statements do not make any reference to opportunities for students to use feedback: feedback may be returned within specified timescales, yet still not be timely in terms of students' learning.

A rationale for turnaround times that focuses on opportunities for students to apply feedback is more representative of a learning-focused approach. This is exemplified by justifications of turnaround times as enabling 'students to use [feedback] in the preparation of subsequent assignments' (TPS, Silver, P92), coming at a time where feedback can 'inform and support the next assessment, maximising its formative benefits' (TPS, Silver, RG). This approach was also evidenced through a focus on programmatic assessment design where opportunities to apply feedback were seen to promote 'deeper learning and allowing students access to greater levels of feedback and feed forward into later summative work' (TPS, Silver, RG).

In some education strategies, institutions spoke of the involvement of students in assessment and feedback design, which can be seen as evidence of a learning-focused approach. In practice, this involved students contributing 'as active partners in the development and improvement of...feedback' (ES, Silver, P92) or being engaged 'in the design and review of assessment and feedback processes' (ES, Silver, RG). These examples stand in contrast to the heavy emphasis on transmission-focused approaches across the corpus as a whole. Such feedback cultures emphasise the importance of student agency in processes traditionally seen as the preserve of academics, by ceding control to enable students to develop ownership over these crucial dimensions of their education.

\section{Feedback practice and purpose}

Approaches to feedback were differentiated according to the extent to which institutions placed emphasis on the actions of teachers or students in the enactment of feedback processes. In a transmission-focused approach, emphasis is placed on teachers' provision of comments and summative feedback. In contrast, learning-focused approaches are evidenced by a stronger focus on the introduction of peer feedback, formative feedback, dialogue and self-assessment. However, even some of these more learning-focused practices were often discussed in terms of the provision of information by teachers rather than use and enactment by students. In many cases, this underpinned claims for excellence, where one institution defined 'an excellent educational experience as one in which students are provided with regular, timely and constructive feedback and 'feed forward' on their learning and progress' (ES, Silver, P92). The term 'provide' here is indicative of emphasis on 
transmission of feedback rather than its use, which was also echoed through terms such as the 'delivery' (ES, Bronze, DI) of feedback.

A stronger learning-focused approach was evident in discussions of practices such as self-assessment and peer feedback, where students played active roles in evaluating the work of themselves and others. These practices placed emphasis on what students do, rather than teachers, where 'feedback is peer-led rather than tutor-led' (TPS, Silver, SI). The outcomes of peer review and self-assessment were frequently described in learningfocused terms, where such activities 'help students understand the purpose and value of assessment' (TPS, Gold, P92), through 'learning collaboratively to gain the skills to selfevaluate the quality of their work' (TPS, Bronze, P92).

Formative feedback processes were positioned as being important in general terms, through strategies that position formative feedback as 'a priority, supported at programme and institutional levels' (ES, Silver, P92). However, in some cases, formative feedback was often positioned as an optional practice that may or may not be taken up by students, described where 'courses should normally have the opportunity for students to either receive feedback on a 'draft' piece of work, or an equivalent formative piece' (ES, Gold, P92), or where 'all modules offer at least one formative assessment opportunity' (TPS, Gold, P92).

In instances where it was a policy requirement for formative feedback opportunities to be offered to students, there was a sense that this could be a box to tick, rather than a practice underpinned by sound pedagogic rationale in relation to students' learning. Targets focusing on the provision of formative feedback opportunities, for example in ' $100 \%$ of modules' (ES, Silver, P92), contrasts with a target pertaining to student uptake of these opportunities, for example striving for ' $80 \%$ of students engaging with formative feedback opportunities' (ES, Bronze, SI).

Ongoing dialogue within feedback processes is another area of practice through which different approaches to feedback were revealed. Some providers sought to create cultures 'rich in formal and informal feedback driven by dialogue between students and between students and their tutors' (ES, Gold, P92), characterised by '1:1 interactions with teaching staff so [students] can ask questions and get feedback as part of the process' (ES, Gold, $\mathrm{RG})$. Some providers demonstrated a specific purpose to the use of dialogue to support student learning, such as supporting synthesis and sense-making of feedback information:

Students are encouraged to meet with their academic tutor at the beginning of each year to reflect holistically on all of the feedback they have received from the last academic cycle, rather than this being limited to one assessment. (TPS, Bronze, SI)

In theory, dialogue is always available but this does not mean that it has a learningfocused approach. This is exemplified by the statement by one provider that in principle further face-to-face explanations of feedback are provided' (TPS, Gold, DI). Whereas students may be 'encouraged to discuss feedback with their module tutor' (TPS, Gold, DI), and 'may also attend weekly office hours with faculty and with class teachers' (TPS, Bronze, RG), this does not mean that it happens, or it may privilege some students over others.

Institutional approaches to feedback are also differentiated by the extent to which students are supported to participate in activities that develop their assessment and feedback literacies. Whereas these activities should involve a learning focus, in many documents, they were often discussed in ways more closely aligned with a transmission-focused approach, where the focus was on providing resources or information in a transactional 
way, without emphasising students' participation in activities or use of this information. For example, assessment criteria were discussed with reference to 'providing comprehensive and timely information to students' (ES, Silver, SI), where 'clearly-explained marking criteria are published in advance of assessments and used to offer feedback when work is returned' (TPS, Gold, DI). The term 'available' was used in many instances, where the role of criteria in developing assessment and feedback literacies was seen to be achieved when 'information is available to students' (TPS, Silver, P92) or 'added to all student handbooks' (TPS, Silver, RG).

Approaches less transactional in nature placed emphasis not on the mere provision of but students' participation in learning activities that support their assessment and feedback literacies, enabling them to 'make more effective use of feedback, improving their own learning and future performance' (TPS, Gold, P92). Students' understanding of criteria could be developed through engagement with 'exemplars as part of classroom activities including examples of feedback given on the assessment, with the aim of supporting the understanding and use of marking criteria' (ES, Gold, P92). One provider discussed workshops designed to develop 'students' understanding of assessment criteria through structured activities including peer-marking and peer feedback' (TPS, Silver, DI). In a few cases, there was evidence of co-construction of resources to support assessment literacy, such as a video created by students to 'demystify the marking process' (TPS, Gold, RG) and the "co-creation of assignment briefs with students, inviting them to critique the description and expectations of the assessment to ensure the language used is clear and accessible' (TPS, Silver, P92).

Beyond the understanding of criteria and standards, learning-focused approaches were signalled by an appreciation that 'in order for students to make effective use of feedback they need to be able to reflect on it and think about changes they can make as a result of the comments' (TPS, Bronze, SI). This aim was achieved in a variety of ways, including supporting 'first year students to understand how to use feedback effectively' (ES, Gold, DI) and enabling students to recognise 'the range of feedback routes and how this feedback may be used'. (TPS, Silver, RG). Some practices bring together students and staff 'in discussions about feedback' (TPS, Silver, DI), and focus on supporting students to 'make the most effective use of the many examples of peer-to-peer feedback' (TPS, Gold, SI).

\section{Development and evaluation of feedback processes}

Approaches to developing and evaluating the effectiveness of feedback processes were differentiated according to emphasis on the quality of the actions of teachers and the feedback they provide to students, versus the quality of interactive processes where students are supported to engage with and use feedback to support their learning. Learning-focused approaches are characterised by approaches to enhancement where emphasis is placed not on what is provided to students, but the impact on their learning. For example, such a learning-focused approach was evidenced by a university-wide review of assessment designed 'to allow all staff and students to engage fully in conversations about appropriate academic practices to support student learning and ambition' (TPS, Silver, P92), and approaches that involve partnership with students 'on an ongoing process of enhancement of assessment and feedback mechanisms' (TPS, Silver, RG). The involvement of students also extends to recognition of staff through awards specifically focused on feedback processes, many of which are student-led. One such example was 
awarded for the impact of feedback on student learning, where students commended a staff member who developed processes involving 'feedback that helps them to move on' (TPS, Silver, SI).

In contrast, in discourse indicative of a transmission-focused approach, some providers discussed the importance of 'policies, processes and systems that ensure high quality and timely assessment feedback is provided to students' (ES, Silver, DI), and 'a widespread initiative to enhance provision of assessment and feedback on student work' (TPS, Gold, DI). This focus on assuring the quality of the provision of feedback was echoed in claims for excellence where 'the quality of feedback provided to students is commended by external examiners across a wide range of subject areas' (TPS, Silver, P92), and where quality audit reports 'affirmed the actions being taken to improve the quality and utility of marker feedback on assessed work, to meet the needs of all students' (TPS, Silver, P92).

Many quality assurance mechanisms have a transmission focus, placing emphasis on 'consistency of practice across course teams in relation to feedback pro-forma and provision of comments on work' (TPS, Silver, P92). Transmission-focused approaches are also characterised by monitoring practices that evaluate the comments provided by teachers, rather than the wider impact of feedback processes, for example, where 'moderators comment on the quality/quantity of feedback provided by the marker(s). Where feedback is found wanting, it is returned to the marker(s) for amendment before being released to students' (TPS, Silver, DI). In discussion of turnaround times, terms such as 'requirement' (TPS, Silver, SI) 'compliance' (TPS, Silver, DI) 'zero tolerance' (TPS, Silver, SI), 'audit' (TPS, Bronze, P92) and 'monitoring' (TPS, Bronze, DI) were commonplace in representing this as an issue of policy rather than learning. Also indicative of a transmission-focused approach was a focus on the impact of practices on student satisfaction, rather than on evidence of impact on student learning. For example, in the context of technology-enhanced feedback processes, some providers sought evidence of their success in 'rates of student satisfaction with assessment and feedback reported through the NSS' (TPS, Bronze, DI).

Given shifts in the literature towards recognition of learning-focused approaches to feedback, approaches to the development of feedback processes that draw upon relevant research literature can be evidence of learning-focused approaches. For example, decisions about development can be 'informed by research and scholarship, practice based projects and real life challenges' (ES, Silver, DI), incorporating 'the insights of research and theory' (ES, Silver P92).

Differing approaches were also identified through discourse around the training and development opportunities provided to staff with regard to feedback processes. In transmission-focused approaches, emphasis was placed on training staff to deliver feedback, and to enact policy requirements, for example by 'ensuring that academic colleagues fully understand the feedback policy' (TPS, Bronze, DI) and 'covering standardised materials and expectations' (TPS, Gold, RG). This may not provide staff with an understanding of why practices may be effective, only the means to enact policy. Stronger learning-focused orientations were identified in cases where staff were supported to develop their practice through an 'Innovation Fund focused specifically on assessment and feedback' (TPS, Gold, DI) and an 'emphasis on CPD that promotes innovation in feedback' (ES, Silver, DI). Thus, transmission-focused approaches focused more heavily on quality assurance; learning-focused approaches were more closely aligned with an ethos of quality enhancement. 


\section{Discussion and implications}

Feedback can be framed in different ways: as a one-way transmission of information driven by educators, or as a more complex process in which students' agentic participation is critical to its success. Despite calls in the literature for a shift away from the former towards the latter (e.g. Carless, 2015), transmission-focused models of feedback continue to dominate practice (e.g. Winstone et al., 2021b). The aim of the present study was to explore the framing of feedback within the education strategies and TEF Provider Statements of 134 UK universities, as a way of characterising 'feedback cultures' within HE.

\section{Framing feedback cultures: implications for policy and practice}

This study adopted an organisational approach to defining feedback cultures, representing the values, beliefs and repertoires of practice that characterise a particular environment (Watling et al., 2020). In their discussion of different approaches to feedback, universities were more likely to refer to the mechanics of transmitting feedback than to the role of feedback in promoting students' learning. A linguistic analysis of the most common verbs with 'feedback' as the object across the data corpus identified students as predominantly passive rather than active participants within feedback processes. In describing the ways in which strategy documents tend to position students, Smith (2008, p. 405) argued that 'Students are frequently represented within the strategies as either an indirect or direct object of a clause: here, the action of the verb is done to them - thus their agency is low'. Similarly, the analysis presented here indicates that the use of verbs representing student action in response to feedback is very minimal; instead, a transactional process of feedback as something that is 'given' and 'received' dominates the way in which practice is described.

Identifying and analysing feedback cultures is important if their influences on practice are to be understood; as argued by Watling et al. (2020, p. 290), 'Culture lurks in the background of our pedagogical practices; its influences on learners are tacit'. Opportunities for learning are therefore supported or stifled through the extent to which the dominant feedback culture in a given setting promotes or precludes particular practices (James \& Biesta, 2007). But how does institutional strategy influence its feedback culture? Strategy documents are not static and inactive; they work to frame and position actors in particular ways, convey what is valued, and actively impact the beliefs and practices of those enacting such documentation (e.g. Atkinson \& Coffey, 2004). For example, if transactional approaches to feedback dominate strategy documents, then such practices are likely to become entrenched in everyday discourse around feedback and valued in further processes such as staff development and promotion. It is likely that a strong transmission focus in documentation communicates to teachers on an implicit level that their role is merely to provide feedback, rather than create environments in which students can learn through engagement with feedback. A transmission focus also positions students as passive receivers of feedback information, rather than agents whose actions play a key role in the impact of feedback processes. As argued by Henderson et al. (2019, p. 1411), 'Institutional policy has an influential role in embedding effective feedback principles in processes, systems and culture'. 
Of course, HEIs may use publicly available documents such as education strategies and TEF Provider Submissions to manage their externally facing image as much as driving practice internally. For this reason, clarity in how strategy and policy should be enacted is crucial if alignment is to be achieved with pedagogic practice; whilst strategies may have the aim of invoking change, there is rarely a simply route to implementation (Clegg \& Smith, 2010), and those who write such documents are often unaware how to make a clear connection between strategic aims and classroom practice (Goodyear \& Ellis, 2019). Institutions may espouse particular practices in making a claim for excellence, yet not enable those practices to flourish through the ways in which they support and recognise staff and students. Furthermore, the actors of policy are not always clearly identified, in part because strategies/policies typically use passive voice (Voce, 2015). Thus, a key recommendation emerging from the analysis is that institutional leaders consider the use of language when writing strategic documentation, and how their desired cultures are communicated on an implicit as well as explicit level. If the dominant culture - as conveyed through key documentary artefacts-is one in which students are positioned as passive recipients of teachers' comments, this may limit the extent to which their engagement is promoted or enabled.

Table 2 presents a summary of the analysis incorporating the different features as extracted through the analysis, with the nature of the feedback culture represented as a continuum. This framework can inform the design of policies and strategies that position students as having agency in feedback processes. The framework could also be used by programme teams to evaluate their processes and consider how a stronger learning-focused culture can be developed.

\section{Limitations and directions for future research}

The present study has underpinned a framework for conceptualising feedback cultures. It is important to acknowledge that this framework is based upon institution-level documentation; individual educators may well represent feedback in more nuanced ways within module/unit-level documentation. Documents solely from the UK context were used to inform the development of this framework; it is therefore important to note that whilst the UK has a strong accountability focus in its HE sector, the challenges inherent to the practice and process of feedback and the practices identified within the framework are not unique to the UK. Nevertheless, it would be beneficial for future work to explore representations of feedback in strategic documentation in other national contexts.

In setting an agenda for future research, the extent to which documentation influences everyday practice in the area of feedback is an important direction. Building upon the seminal work of Trigwell and Prosser (1996), it is important to understand whether learning-focused feedback cultures are more likely to lead educators to focus on their role in creating environments for students to learn from feedback, rather than on just their transmission of comments. In turn, it is important to understand how students' behaviour, in terms of their own engagement with feedback processes, is influenced by the feedback culture. There is a crucial role for educators in effective feedback processes, but the role of students is more important. Educators can create environments which afford students agency in feedback processes, but relegating students to the receiving end of teacher transmission of comments is unlikely to result in effective feedback processes. 


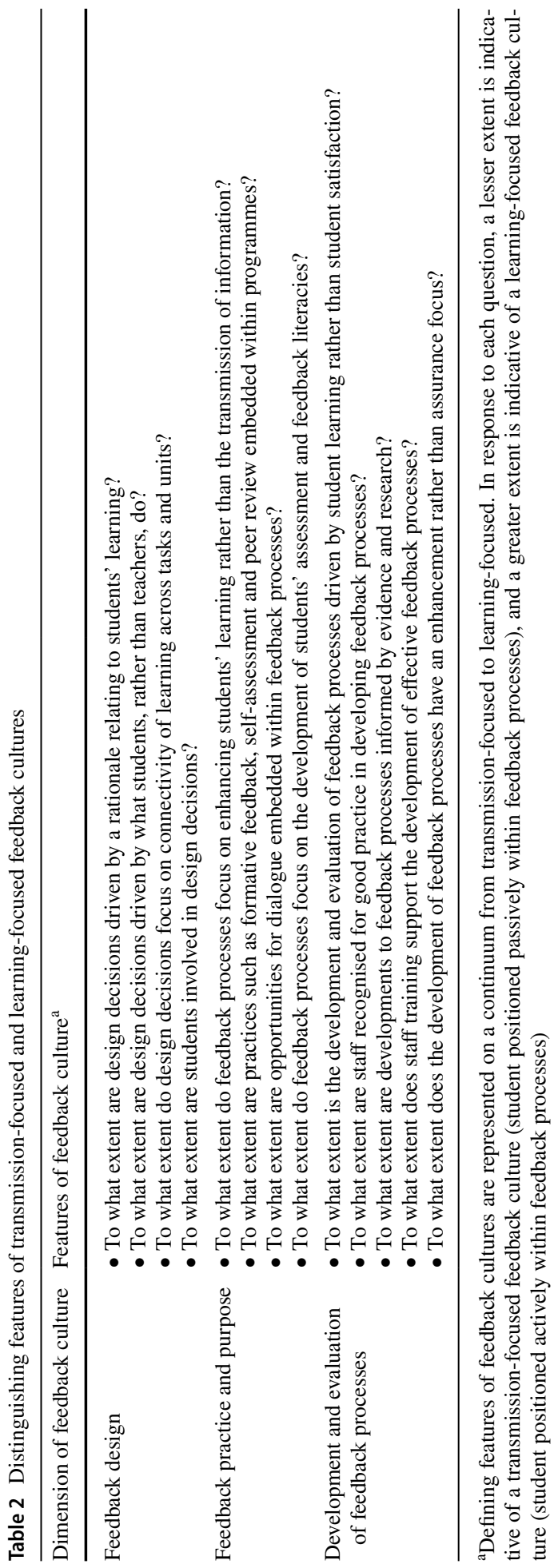


Acknowledgements The author acknowledges the assistance of Emily Papps and Molly Foster with data coding, Dr Kieran Balloo for his support with reliability coding and Dr Robert Nash and Professor Ian Kinchin for helpful comments on an earlier draft of this article.

Funding This study was funded by the Society for Research into Higher Education through the award of a research grant (RA1648).

\section{Declarations}

Competing interests The author declares no competing interests.

Open Access This article is licensed under a Creative Commons Attribution 4.0 International License, which permits use, sharing, adaptation, distribution and reproduction in any medium or format, as long as you give appropriate credit to the original author(s) and the source, provide a link to the Creative Commons licence, and indicate if changes were made. The images or other third party material in this article are included in the article's Creative Commons licence, unless indicated otherwise in a credit line to the material. If material is not included in the article's Creative Commons licence and your intended use is not permitted by statutory regulation or exceeds the permitted use, you will need to obtain permission directly from the copyright holder. To view a copy of this licence, visit http://creativecommons.org/licenses/by/4.0/.

\section{References}

Ashwin, P. (2017). What is the Teaching Excellence Framework in the United Kingdom, and will it work? International Higher Education, 88, 10-11.

Atkinson, P., \& Coffey, A. (2004). Analysing documentary realities. Qualitative Research, 3, 77-92.

Barkas, L. A., Scott, J. M., Poppitt, N. J., \& Smith, P. J. (2019). Tinker, tailor, policy-maker: Can the UK government's teaching excellence framework deliver its objectives? Journal of Further and Higher Education, 43(6), 801-813.

Berger, D., \& Wild, C. (2016). The Teaching Excellence Framework: Would you tell me, please, which way i ought to go from here. Higher Education Review, 48(3), 5-22.

Boud, D., \& Molloy, E. (2013). Rethinking models of feedback for learning: The challenge of design. Assessment \& Evaluation in Higher Education, 38(6), 698-712.

Bowen, G. A. (2009). Document analysis as a qualitative research method. Qualitative Research Journal, 9(2), 27-40.

Braun, V., \& Clarke, V. (2006). Using thematic analysis in psychology. Qualitative Research in Psychology, 3(2), 77-101.

Carless, D. (2015). Excellence in university assessment: Learning from award-winning practice. Routledge.

Carless, D., \& Boud, D. (2018). The development of student feedback literacy: Enabling uptake of feedback. Assessment and Evaluation in Higher Education, 43(8), 1315-1325.

Clegg, S., \& Smith, K. (2010). Learning, teaching and assessment strategies in higher education: Contradictions of genre and desiring. Research Papers in Education, 25(1), 115-132.

Deem, R., \& Baird, J. A. (2019). The English Teaching Excellence (and Student Outcomes) Framework: Intelligent accountability in higher education? Journal of Educational Change, 1-29.

Gibbs, G., Habeshaw, T., \& Yorke, M. (2000). Institutional learning and teaching strategies in English higher education. Higher Education, 40(3), 351-372.

Goodyear, P., \& Ellis, R. A. (2019). Ecological thinking about education strategy in universities. In R. Barnett \& N. Jackson (Eds.), Ecologies for Learning and Practice (pp. 97-111). Routledge.

Henderson, M., Phillips, M., Ryan, T., Boud, D., Dawson, P., Molloy, E., \& Mahoney, P. (2019). Conditions that enable effective feedback. Higher Education Research and Development, 38(7), 1401-1416.

Henderson, M., Ajjawi, R., Boud, D., \& Molloy, E. (2019a). Identifying feedback that has impact. In M. Henderson, R. Ajjawi, D. Boud, \& E. Molloy (Eds.), The impact of feedback in higher education: Improving assessment outcomes for learners (pp. 15-34). Springer.

Henderson, M., Ajjawi, R., Boud, D., \& Molloy, E. (2019b). Why focus on feedback impact? In M. Henderson, R. Ajjawi, D. Boud, \& E. Molloy (Eds.), The impact of feedback in higher education: Improving assessment outcomes for learners (pp. 3-14). Springer. 
James, D. (2014). Investigating the curriculum through assessment practice in higher education: The value of a 'learning cultures' approach. Higher Education, 67(2), 155-169.

James, D., \& Biesta, G. (2007). Improving learning cultures in further education. Routledge.

Lombard, M., Snyder-Duch, J., \& Bracken, C. C. (2002). Content analysis in mass communication: Assessment and reporting of intercoder reliability. Human Communication Research, 28(4), 587-604.

National Committee of Inquiry into Higher Education (1997), Higher Education in the Learning Society, Report of the National Committee, HMSO, Norwich.

Newton, J. (2003). Implementing an institution-wide learning and teaching strategy: Lessons in managing change. Studies in Higher Education, 28(4), 427-441.

O’Donovan, B., Rust, C., \& Price, M. (2016). A scholarly approach to solving the feedback dilemma in practice. Assessment \& Evaluation in Higher Education, 41(6), 938-949.

Page, C., Baker, H., \& Myerholtz, L. (2021). Using a Delphi technique to define a feedback culture in graduate medical education. Family Medicine, 53(6), 433-442.

Ramani, S., Könings, K. D., Mann, K. V., Pisarski, E. E., \& van der Vleuten, C. P. (2018). About politeness, face, and feedback: Exploring resident and faculty perceptions of how institutional feedback culture influences feedback practices. Academic Medicine, 93(9), 1348-1358.

Roxå, T., Ahmad, A., Barrington, J., Van Maaren, J., \& Cassidy, R. (2021). Reconceptualizing student ratings of teaching to support quality discourse on student learning: A systems perspective. Higher Education, Advance Online Publication.

Shah, M., \& Richardson, J. T. (2016). Is the enhancement of student experience a strategic priority in Australian universities? Higher Education Research and Development, 35(2), 352-364.

Skelton, A. (2005). Understanding teaching excellence in higher education: Towards a critical approach. Routledge.

Smith, K. (2008). 'Who do you think you're talking to?'- the discourse of learning and teaching strategies. Higher Education, 56(4), 395-406.

Tomlinson, M., Enders, J., \& Naidoo, R. (2020). The Teaching Excellence Framework: Symbolic violence and the measured market in higher education. Critical Studies in Education, 61(5), 627-642.

Trigwell, K., \& Prosser, M. (1991). Relating approaches to study and quality of learning outcomes at the course level. British Journal of Educational Psychology, 61(3), 265-275.

Trigwell, K., \& Prosser, M. (1996). Congruence between intention and strategy in university science teachers' approaches to teaching. Higher Education, 32(1), 77-87.

Trigwell, K., Prosser, M., \& Waterhouse, F. (1999). Relations between teachers' approaches to teaching and students' approaches to learning. Higher Education, 37(1), 57-70.

Van der Kleij, F. M., Adie, L. E., \& Cumming, J. J. (2019). A meta-review of the student role in feedback. International Journal of Educational Research, 98, 303-323.

Voce, J. (2015). Reviewing institutional policies for electronic management of assessment. Higher Education, 69(6), 915-929.

Watling, C. J., Ajjawi, R., \& Bearman, M. (2020). Approaching culture in medical education: Three perspectives. Medical Education, 54(4), 289-295.

Winstone, N. E., \& Boud, D. (2019a). Developing assessment feedback: From occasional survey to everyday practice. In S. Lygo-Baker, I. M. Kinchin, \& N. E. Winstone (Eds.), Engaging student voices in higher education: Diverse perspectives and expectations in partnership (pp. 109-123). Palgrave.

Winstone, N. E., \& Boud, D. (2019b). Exploring cultures of feedback practice: The adoption of learningfocused feedback practices in the UK and Australia. Higher Education Research and Development, $38(2), 411-425$.

Winstone, N. E., \& Carless, D. (2019). Designing effective feedback processes in higher education: A learning-focused approach. Routledge.

Winstone, N. E., Ajjawi, R., Dirkx, K., \& Boud, D. (2021a). Measuring what matters? The positioning of students in feedback processes within national student satisfaction surveys. Studies in Higher Education, Advance Online Publication.

Winstone, N. E., Pitt, E., \& Nash, R. A. (2021b). Educators' perceptions of responsibility-sharing in feedback processes. Assessment and Evaluation in Higher Education, 46(1), 118-131.

Publisher's note Springer Nature remains neutral with regard to jurisdictional claims in published maps and institutional affiliations. 